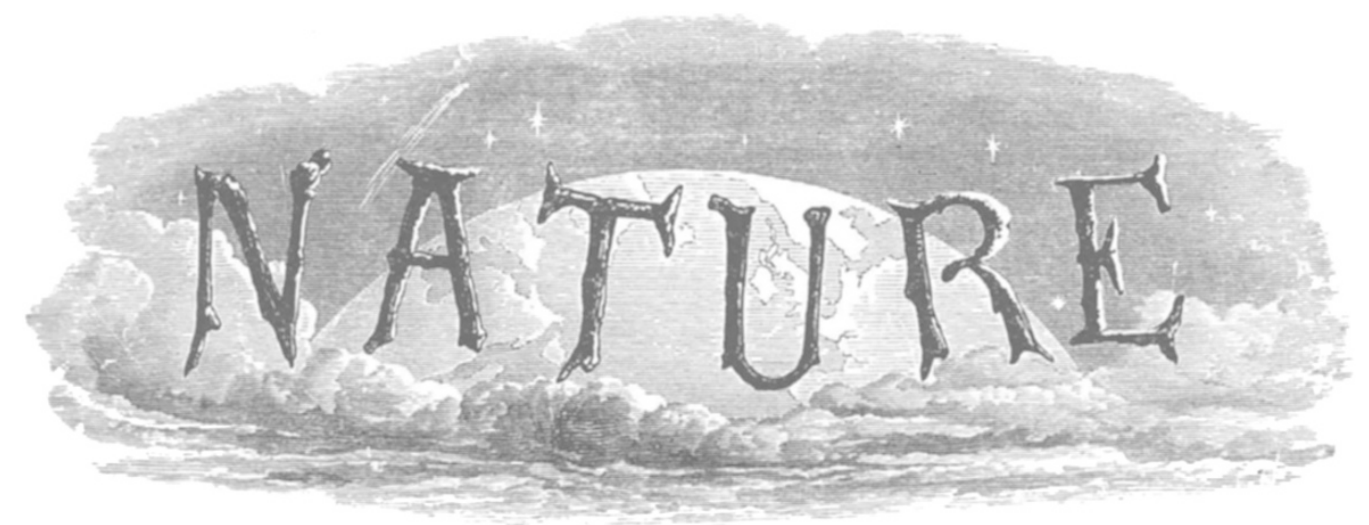
A W E E K L Y
$J$ O U R N A L
"To the solid ground
O F S C I E N C E

of Nature trusts the mind that builds for aye."-WORDSWORTH.

SATURDAY, JULY I, 1933

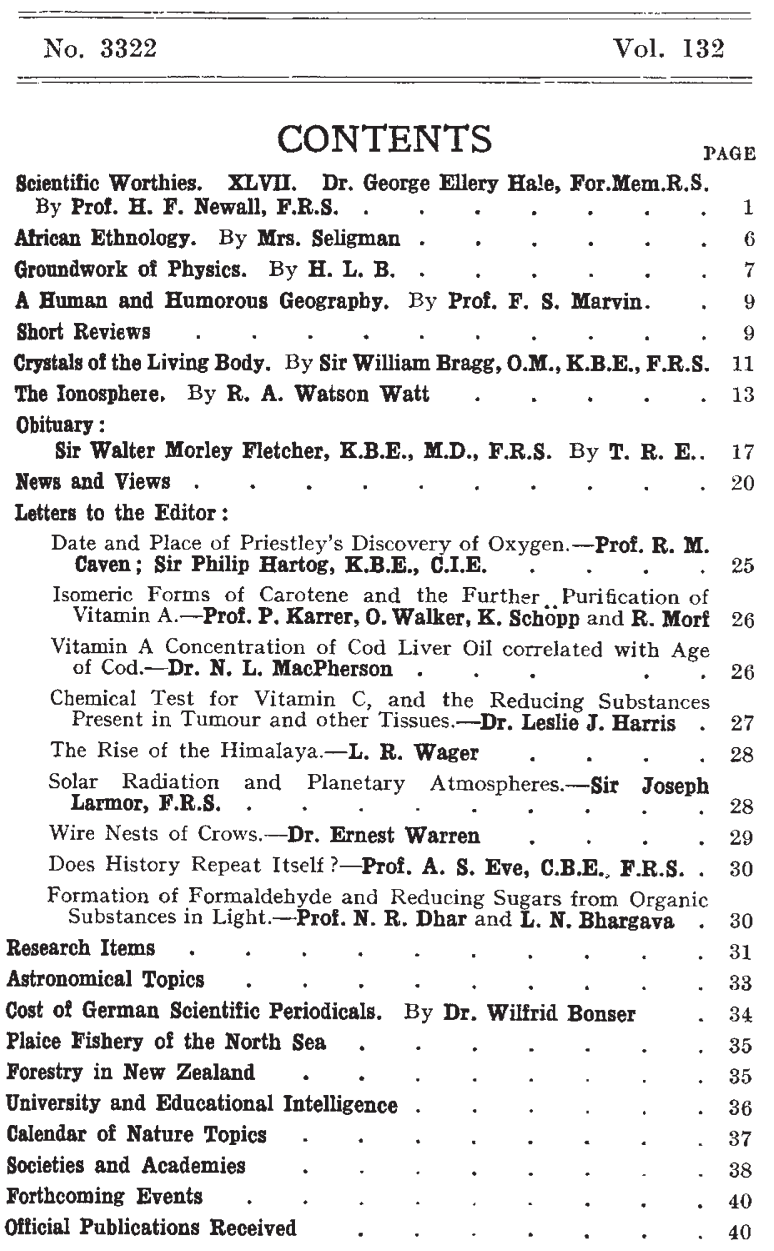

\section{Scientific Worthies}

\section{XlViI. George Ellery Hale}

T $\mathrm{HE}$ advance of science is sometimes described as taking place by leaps and bounds. This mode of expression serves to indicate the rapidity of general progress, but it scarcely suggests the existence of the long intervals in which stagnation was the notable feature in the advance of special branches of scientific investigation. Advance in one branch is frequently at a standstill, until some discovery in another subject has been made and found to be available in wider fields.

This has been markedly the case in the study of solar phenomena. The invention of the telescope in 1610 led to the observation of sunspots, but it needed the passage of two centuries before the periodic variation in the frequency of sunspots was discovered by the apothecary Schwabe, from his personal observations assiduously recorded during many years. Wollaston's and Fraunhofer's study of absorption lines in the solar spectrum had to wait for half a century before explanation was forthcoming at the hands of Foucault and of Stokes, and of Bunsen and Kirchhoff. Yet another half-century was to pass before the advance of astrophysics could be said to have arrived at the exciting time of leaps and bounds, when a multitude of contributors had found the technique of studying the complex phenomena which gave promise of disclosing the nature of the systematic differences between one star and another, with a 
unique specimen-the sun-to provide us with means of detailed study.

Helmholtz had suggested that the processes of gravitation in the sun itself must be the source of the continual emission of heat and light from the sun, and so probably from the stars also; but radioactivity had not then been discovered. Dryplate photography had displaced the tedious processes of the wet plate, and the range of sensitiveness to light of different colours had to be extended by the use of special sensitisers. Janssen and Lockyer had shown how the extensive prominences round the limb of the sun could be seen visually with the aid of the spectroscope. Lockyer had directed attention to the importance of enhanced lines in spark spectra. Huggins had fathomed the secret of the gaseous nebulæ and had led the way, which was so splendidly followed by Vogel, Keeler, and Campbell, in measuring the radial motions of the stars.

It was into this exciting time that George Ellery Hale emerged from boyhood, with an unusual eagerness for the study of natural objects with home-made appliances. He was born in Chicago in 1868. Three years later the great fire destroyed most of his native city and left those who, like Hale's father, had property there, involved in heavy losses. William Ellery Hale was an energetic optimist, and whilst carrying on his business of manufacturing hydraulic elevators, he recognised the constructive ability of his son and developed it with true wisdom and understanding. Improved tools and microscopes were to be earned by successful work spent in making full use of makeshift apparatus and in devising and improving methods and instruments to special ends.

Whilst the father rewarded industry by the gift of a lathe or a Beck binocular microscope and tried to control undue eagerness by a remonstrance that his son was always "wanting to do it yesterday", the mother saw to it that her son gained a lively interest in good literature both ancient and modern. Grimm's "Fairy Tales", "Don Quixote", translations of Homer's "Iliad" and "Odyssey", were supplemented by Cassell's "Book of Sports and Pastimes", and later by Darwin's "Origin of Species". There was a possibility at one time of bis boyhood that Hale should become a zoologist, and even to the present day it is no easy matter to get him to pass a woodland pool without his wishing to search for a Cyclops or a branchiopod or a Vorticella. But the joy of making, using and designing instruments for special purposes carried the day, and by the time his boyhood was com. pleted he had himself constructed his own private workshop and a spectroscopic laboratory.

These details may seem out of place in an article like the present, but they have a high interest as bearing on the development of breadth of outlook, justification of bold enterprise by full use of experience, and single-hearted desire to contribute to the welfare of a generation by personal stimulation of co-operation in the multifarious lines of human endeavour. These qualities have been marked features in Hale's life.

It was clear that the Massachusetts Institute of Technology was likely to satisfy Hale's desires as a place of directed study, and in 1889 , before the completion of his courses, he had made trials, at the Harvard College Observatory, of the first model of the spectroheliograph, the instrument which he developed later to great perfection step by step.

The choice of the subject of a life's work is a very arbitrary and chancy affair, and Hale's choice was made when he was at the beginning of his studies (1886-1890). Probably the proximity of the Harvard College Observatory, and the stim. ulating influence of E. C. Pickering, and of C. A. Young at Princeton helped to confirm his devotion to what is now known as astrophysics; but he was a confirmed amateur spectroscopist and solar observer before he went to Boston. The work of Secchi, Huggins and others had shown how one star "differeth from another" and how a system of stellar types was disclosed by the study of the details of the spectra of hundreds of stars. To a young mind that was already moved enthusiastically by Darwin's ideas of natural evolution in the gradual development of the various forms of living objects, the way seemed open to still wider application of evolutionary ideas in the interpretation of celestial phenomena.

It was not that Hale was a lonely pioneer in this appreciation of the vastness of the field of research thus opened out. But it afforded him the motive power to the great endeavours which have marked his life's work.

Hale finished his courses at the "Mass. Tech." in the summer of 1890. A visit to California and to the Lick Observatory, with his wife (married two days after his graduation), made a lasting impression on his mind. Holden was then director of the Observatory, and Keeler was on the staff in charge of the spectroscopic observations. Hale had great difficulty in resisting Holden's offer of the 36-in. 
refractor for use in developing the spectroheliograph. The greater freedom for work with a smaller instrument of his own weighed strongly with Hale, and he returned to Chicago to talk the matter over with his wise father. The result of the consultation was an order for a 12-in. refractor with a suitable mounting incorporating Hale's designs. Thus the Kenwood Observatory was founded, on the same site as Hale's spectroscopic laboratory, about a mile north of the buildings of the University of Chicago.

A most notable feature in Hale's work has been the regular succession of advances based on successive experiences and leading to constantly increased power of instrumental equipment on novel lines.

It was a fortunate chance that led him to his first choice of study in spectroscopic observation of solar prominences. His recognition of the marked brilliance of the $H$ and $K$ lines of calcium in those prominences led him to concentrate his efforts first in obtaining photographic records of the prominences at the sun's limb, and then in the systematic search for signs of such phenomena over the whole visible disc of the sun. The observations of Janssen and of Lockyer during the total eclipse of the sun in 1868 had shown the way to detect prominences at the limb in full uneclipsed sunshine, but the delineation of them in visual observations was a tedious process, involving as it did the building up of a picture by recording in their drawings the successive changes in the distribution of bright points in the monochromatic image of the slit of the spectroscope, as the suspected prominence was allowed to move across the primary slit. Even Huggins's method of widening the primary slit had its drawbacks; for though it served to reveal the form of the brighter parts of a prominence, the more delicate parts were lost in the increased brilliance of the background.

Hale's invention of the spectroheliograph achieved what was required by the simple expedient of retaining a narrow primary slit and introducing a narrow secondary slit in a chosen part of the spectral image in the camera, to allow only the light of a chosen monochromatic image of the primary slit to pass through. A photographic plate, placed behind the secondary slit, was moved across that slit with equable speed, and so was made to record the instantaneous impressions whilst the primary image of the prominence on the primary slit moved equably across that slit.
The photographic plate necessarily recorded the form of the prominence in the monochromatic light transmitted by the secondary slit, and when that light was that of the $H$ or $K$ lines of calcium, the form of the prominence was depicted in terms of that kind of light, and it was found that the form was in most respects similar to that depicted when one of the bright spectral lines of hydrogen was employed. The utilisation of the $K$ line had a great advantage, namely, that in the solar spectrum the $K$ line is a very broad absorption line $\left(K_{1}\right)$ with a narrow emission line $\left(K_{2}\right)$ at its centre, this emission line having a dark reversal $\left(K_{3}\right)$ at its middle point. Hale's interpretation of these features was immediately helpful; he regarded $K_{1}$ as ascribable to calcium vapour seated low in the solar reversing layer under considerable pressure; the bright $K_{2}$ as being due to vapour higher in the solar atmosphere, and he ascribed $K_{3}$ to the absorption produced by the calcium vapour high above that producing the $K_{2}$ line.

Success, achieved in the Kenwood Observatory, in photographing isolated prominences, was followed at once by success in obtaining record in a single photograph of all the prominences round the whole limb of the sun. It was then found by photographic spectroscopic observations that the bright $K_{2}$ line could be detected here and there even on the bright disc of the sun. This suggested that masses of calcium vapour might be observed not only projecting edgewise from the limb of the sun but also passing over the bright disc of the sun. Spectroheliograms of the disc of the sun were accordingly undertaken, and disclosed the existence of great regions where the calcium vapour was glowing in huge clouds, clustering in general over and about sunspots. Hale recognised that the phenomena thus disclosed required a new terminology, and he later coined the word flocculi to distinguish these from faculce, which was the name then in use to describe the bright areas of the sun's surface, such as are disclosed for example in Janssen's large-scale direct photographs of the solar surface in integrated sunlight.

At the Kenwood Observatory, this new study of the sun's surface was carried out by Hale in the years 1891-93, and with the help first of his brother and sister and later of his devoted assistant Ellerman, some three thousand photographs were obtained of these novel phenomena, disclosing as they did the close relationship of the floccular zones with the sunspot zones.

Then followed a period of great activity for 
Hale. He learnt of the existence of two 40-in. dises of glass in the hands of Alvan Clark, and set himself the task of finding means of securing them for an observatory to be connected with the University of Chicago, a task that was made practicable by the munificence of $\mathrm{Mr}$. Charles $\mathrm{T}$. Yerkes. The site was chosen at Lake Geneva, near the southern boundary of the State of Wisconsin, at a height of more than eleven hundred feet above sea level, and at a distance of about sixty miles north-north-west of Chicago.

While the observatory was being built and the 40-in. refractor was being constructed, Hale carried on his observations at Kenwood and took steps to found the Astrophysical Journal. Later he developed the Rumford spectroheliograph-an instrument weighing about $700 \mathrm{lb}$. and capable of securing photographs of the sun's disc on a scale of about $6 \frac{1}{2}$ in. to the diameter of the image. His mind being set also on the study of stellar spectra on lines of the evolution of stars, the stellar spectrograph was constructed and utilised specially in the study of the spectra of stars of Secchi's fourth type. He had secured the co-operation of Barnard, Burnham and of E. B. Frost; and the work at the Yerkes Observatory went forward for ten years under Hale's directorship.

Then came the possibility of large financial assistance from the Carnegie Institution for the foundation of a Solar Observatory, and Hale was encouraged to seek better conditions of astronomical seeing and more congenial climate in Southern California, where admirable sites had been found. Hale decided to go to the site of Mount Wilson which, after careful observations made by Hussey and others, had been found to offer much better conditions than were available for astronomical work at the Yerkes Observatory. $\mathrm{He}$ realised that better results for solar observations could be obtained by the use of a beam of sunlight directed in a fixed azimuth by heliostats or cœlostats, so that more massive spectroheliographic apparatus could be utilised on fixed platforms than could be manipulated at the eye end of an equatorially mounted refractor. The work accomplished at Lake Geneva with the Snow telescope served to show the advantages of that form of instrument, but it ended tragically in a firestarted by the fusing of electric mains and resulting in the destruction of a large part of the optical equipment. The instruments were rebuilt through a gift from Miss Snow and afterwards were lent to Hale by the new director, Frost, and Miss Snow made further contributions to enable Hale to com. plete the trials on the new site on Mount Wilson.

It was characteristic of Hale's thorough method of procedure, that, in order to find out whether atmospheric tremor diminished appreciably when the required optical beam of sunlight was caught several feet above the surface of the ground, he made observations of the sun at different heights up an available fir tree, and they convinced him that definite improvement in the seeing was gained even $30 \mathrm{ft}$. above the ground, and still better results were obtained at $75 \mathrm{ft}$. So the site for the new Snow telescope was chosen on ground sloping downwards to the north, so that the cœlostat system could be placed on a lofty pier at the south end, directing the optical beam northwards, sloping downwards at an inclination of $15^{\circ}$. Soon another experiment was tried, in the form of a tower telescope, a lattice-girder structure carrying cœlostat and a 12-in. object glass at the top, forming a 6 in. image of the sun at ground level $60 \mathrm{ft}$. below, whilst the massive spectrographic apparatus was sunk vertically downwards into a dry well which served to keep equable temperature.

The successes achieved with these arrangements completely justified the large expenditure involved. The more powerful instruments enabled Hale to study spectroheliograms taken in the light of the much narrower hydrogen lines, and they disclosed. the facts that the hydrogen flocculi appeared to require description as if they were dark masses in large regions where the calcium flocculi were usually bright, and, most important of all, that vortical structure was exhibited in the arrangement of the hydrogen flocculi round sunspots. This work was in large measure rendered possible in 1908 by the advances made in sensitising photographic plates in such a way that the flocculi could be studied in the light of the red hydrogen line $(H \alpha)$.

Then followed the bold enterprise of a search for evidence of the existence of magnetic fields in the vortices round sunspots. Zeeman's discovery of the peculiar structure elicited in the bright monochromatic lines in the spectra of various chemical elements when they are made to glow in a strong magnetic field, provided Hale with the means of discovering that sunspots were seats of strong magnetic fields. He had to work with absorption lines in the solar spectrum, and to recognise in them the Zeeman fine structure with the aid of delicate polariscopic apparatus. 
Here came in the immense importance of Hale's policy of linking the astronomical work with investigations in fully equipped physical laboratories connected with the Observatory; and Hale's remarkable faculty of organising teamwork resulted in the development of a very beautiful technique in studying the Zeeman effect in a multitude of selected lines in the spectra of various elements, chosen by reason of the marked prominence of those lines seen to be affected by widening and enhancement in the spectra of sunspots. By the use of a compound quarter-wave mica plate and a Nicol prism, placed over the slit of the $30 \mathrm{ft}$. spectrograph in the dry well beneath the $60 \mathrm{ft}$. tower telescope, Hale succeeded in obtaining proof of the existence of intense magnetic fields in sunspots. Moreover, by the beautiful technique which he had devised for gaining complete information about the intensity of the magnetic field in different parts of a group of spots, he discovered that most groups could be classified as bipolar in the sense that the preceding spot had a polarity opposite to that in the following component. Furthermore, he discovered, in the passage of time in the eleven-year cycle of frequency of sunspots, that the relative polarities of bipolar groups of spots changed in passing through the years of minimum frequency of sunspots, thus indicating that the sunspot cycle should be regarded as involving a periodicity twice as great as that hitherto generally accepted.

The success of this achievement provided Hale with a beautiful instance of bold enterprise to be based on the utilisation of the experience gained in the use of the $60-\mathrm{ft}$. tower telescope. $\mathrm{He}$ planned a tower telescope $150 \mathrm{ft}$. in height, capable of giving an image of the sun $16 \mathrm{in}$. in diameter at ground level, to be examined with a spectrograph $75 \mathrm{ft}$. long, placed in a dry well sunk vertically below the tower, and provided with a diffraction grating, which in the third order of spectrum gave dispersion sufficient to show the Zeeman effect that could be attributed to a general magnetic field over the whole surface of the sun. The observations have justified the conclusion that the sun is a magnet with its poles lying at or near the poles of rotation.

It may well be imagined that a dome large enough to shield the cœlostat and object glass at a height of $150 \mathrm{ft}$. above ground would be exposed to great shaking from the winds at that height over the mountain. These risks and difficulties were surmounted by the device of mounting the mirrors and lenses on a skeleton tower, with each member (leg or cross bracing) encased in a corresponding hollow member of another latticegirder tower with clearance enough to prevent contact.

Hale's policy of arranging a fully equipped machine shop in connexion with the Observatory provided him with the means of supervising the construction of instruments devised to meet the requirements of research. Thus the mirror of the 60 -in. reflector was begun by Ritchey in the workshops of the Yerkes Observatory and was worked and figured at Pasadena. Similarly the 100-in. mirror, provided by the munificence of John D. Hooker, of Los Angeles, was worked and figured in the workshops of Mount Wilson Observatory at Pasadena. This splendid instrument has already more than justified its construction by providing Hubble with the means of studying the spectra of the remote spiral nebulæ, which are now regarded as island universes far beyond the limits of our immediate galactic universe. These spectra disclose radial motions of the spiral nebulæ far greater than the motions within the galaxy, and they are interpreted as indications of expansive actions tending to lead to dispersal of the superuniverse with ever-increasing velocities.

The same 100-in. reflector has also provided, in virtue of its massive mounting, means of applying Michelson's interferential method for gauging the diameters of giant stars. The results help to encourage us with increased confidence not only in the previous theoretical estimates of these enormous extensions of isolated stars, but also in the correctness of our views of the nature of stellar evolution. The results obtained in the extension of our knowledge of the outlying parts of the universe have been such as to justify a further increase in the light-gathering power of even larger instruments, and much thought and exploratory work have been expended on the problems of building a reflector of 200 -in. diameter, with the help of subsidies from the Rockefeller Funds, to be attached to the California Institute.

Throughout the development and utilisation of the observational equipment, Hale has found energy and time to devote to fostering co-operative schemes not only in his own country but also among the leading nations. It was at his instiga. tion that the International Union for Co-operation in Solar Research was suggested about the year 
1904, resulting in meetings, first at Oxford in 1907, then at Meudon in 1907, and at Mount Wilson in 1910. At the last-named meeting, it was decided to extend the scope of the Solar Union, and thus finally arose the International Astronomical Union, which has met triennially and embraces a multitude of commissions charged with the organisation of observations for accelerated research. Largely under Hale's instigation, too, the National Research Council was established in Washington under the auspices of the National Academy of Sciences.

It is in no way surprising that the demands of such activity should result in the impairment of strength of one so deeply engaged as Hale has been through the whole of his life. Still his indomitable spirit enables him not only to carry out further extensions of observational investigations with his novel instrument, the spectrohelioscope, but also to devote much energy to such varied matters as the organisation of the very valuable Huntington Library and Art Gallery for the purposes of research in literary and artistic subjects, the active participation in town planning in Pasadena, and furthering the extensive aims of the California Institute of Technology under Professors Millikan and Noyes and others and, particularly, stimulating co-operation between that Institute and the staff of Mount Wilson Observatory in investigations contemplated in the Institute's Astrophysical Observatory, which is to contain the 200 -in. reflector.

All his many colleagues and friends over the wide world join in congratulating Hale on his great achievements and in wishing him health and strength to continue to completion his present tasks in his observations with the spectrohelioscope and in his intensive search for new methods of studying the general magnetic field of the sun.

H. F. Newall.

\section{African Ethnology}

The Tribes of the Ashanti Hinterland. By Capt. R. S. Rattray. With a Chapter by Prof. D. Westermann. Vol 1. Pp. xxxii $+292+15$ plates. Vol. 2. Pp. xi $+293-604+69$ plates. (London: Oxford University Press, 1932.) 2 Vols., $45 s$. net.

$\mathrm{I}^{\mathrm{N}}$ $\mathrm{N}$ his work on the tribes of the Ashanti Hinterland, Capt. Rattray has brought to light a mass of material for which all anthropologists must be grateful, while as an administrator, he has been at pains to investigate those aspects of native thought and organisation that must be understood if 'indirect rule' is to be put into operation successfully.

The area in question has suffered no important northern migration or other alien influence, and except for a relatively small enclave, there has been no attempt to form a centralised government. Only in the north-east, among the Dagomba and Mamprusi, are there important territorial chiefs, with court officials and regular ceremonies of 'enstoolment' similar to those of Ashanti. Here Capt. Rattray was able to trace this organisation to the settlement of Akan mercenaries, the Chakosi, who, called in by the Mamprusi, remained to conquer the neighbouring tribes. The mass of the territory forms a cultural unit, with tribal grouping and totemic clan organisation under 'priest-kings', there being a strong tendency for territorial grouping of the clans. It may be questioned whether 'priest-king' was a wise translation of ten'dana, which the author shows clearly to mean 'owner of the land'. 'The 'owner' is not the possessor but the spiritual trustee, on whose duties the prosperity of the land depends. He is not a 'divine king', as the king of the Shilluk or the Dinka rain-maker, but more closely resembles the 'father of the land' among the Bari or Lotuko, or the dugutigi, 'master of the soil', of the Banmana in French territory, one difference being that in the Sudan the clans are usually scattered, so that the 'father of the land' is not the head of the clan and has little authority. The ten'dana has, or had, considerable power and social distinction. Capt. Rattray tells us little about his actual duties, but they are in the main religious, disputes being settled by the head of the clan section, though the ten'dana will sit with the elders in council.

It must not be thought that religious duties are less important than legislative duties to these tribes. No peoples have been described in closer and more continual contact with their spirits. By means of soothsayers the spirits are consulted on all occasions, and their wishes made known to their descendants; but even without the mediation of the soothsayer, close touch is kept with the spirits by means of shrines, which every householder possesses. Besides the spirits of parents and ancestors, every individual has a guurdian spirit, segere. For every child the soothsayer indicates at a certain time which spirit has become its segere; it is frequently found to be 